\title{
Source processes of the 2009 Irian Jaya, Indonesia, earthquake doublet
}

\author{
Natalia Poiata, Kazuki Koketsu, and Hiroe Miyake \\ Earthquake Research Institute, University of Tokyo, 1-1-1 Yayoi, Bunkyo-ku, Tokyo 113-0032, Japan
}

(Received April 14, 2009; Revised February 8, 2010; Accepted February 22, 2010; Online published July 9, 2010)

\begin{abstract}
On January 3, 2009 UT, an earthquake doublet with moment magnitudes of 7.6 and 7.4 occurred along the New Guinea trench near the northern coast of Irian Jaya, Indonesia. The events were separated by three hours in time and $60 \mathrm{~km}$ in space, having similar thrust faulting mechanisms. The Solomon and New Britain Islands regions located east of the source area are well known for the occurrence of earthquake doublets due to the complex tectonic settings. To investigate the source processes of the earthquake doublet, we have performed teleseismic waveform inversions using $P$-wave displacement records from the IRIS-DMC database. The results of the inversions are consistent with the direction of the subduction along the New Guinea trench for both of the earthquakes. Significant slips exceeding $5.0 \mathrm{~m}$ appear near the hypocenters, and the slip distributions look to be complementary to each other. The rupture starting point of the second event is close to the edge of the slip distribution of the first event. Our source models support the triggering mechanism of doublet events suggested by Lay and Kanamori (1980). The results also suggest the state of stress in the Irian Jaya region and the mechanism of earthquakes in this subduction zone.
\end{abstract}

Key words: Earthquake doublet, New Guinea trench, waveform inversion, source process, triggering.

\section{Introduction}

An earthquake doublet occurred on January 3, 2009 UT along the northern coast of Irian Jaya, eastern Indonesia. As the result of this earthquake doublet, five people were killed, several hundred were injured, and around 800 buildings were damaged in the cities located close to the epicentral area (USGS Earthquake Summary Poster, 2009). According to the Global Disaster Alert and Coordination System (GDACS), the tsunami generated by this earthquake doublet reached a height of $1.8 \mathrm{~m}$ in the coast region of Irian Jaya, though no tsunami warning was issued. As reported by USGS, the first event of moment magnitude $\left(M_{\mathrm{w}}\right) 7.6$, occurred at 19:43:54 UT. Three hours later at 22:33:42 UT, the second event of $M_{\mathrm{w}} 7.4$ took place $60 \mathrm{~km}$ east of the first one. The USGS located the epicenters of the events close to the northern coastline of Irian Jaya, which is the western part of the New Guinea Island, and the westernmost part of the New Guinea trench (Fig. 1). They are about $400 \mathrm{~km}$ west of the $M_{\mathrm{w}} 8.2$ earthquake on February 17, 1996. Around 100 people were killed by this large offshore earthquake and associated tsunamis.

Eastern Indonesia is located inside the region of complex tectonics controlled by the motions of the Eurasia, Australia, Pacific, Philippine Sea, and numerous small plates (Fig. 1). This area is also known for its high seismic activity with frequent events of magnitude 7 to 8 . Within the Irian Jaya region, the Australia plate collides with the oceanic Pacific and Philippine Sea plates at a rate of $110 \mathrm{~mm} / \mathrm{yr}$ and

Copyright (C) The Society of Geomagnetism and Earth, Planetary and Space Sciences (SGEPSS); The Seismological Society of Japan; The Volcanological Society of Japan; The Geodetic Society of Japan; The Japanese Society for Planetary Sciences; TERRAPUB.

doi:10.5047/eps.2010.02.008 an azimuth of 245 degree (DeMets et al., 1990). GPS measurements of crustal deformation (Puntodewo et al., 1994; Bock et al., 2003) and seismic profiling studies (Milsom et al., 1992) show that the convergence between the Australia and Pacific plates in the Irian Jaya region is partially accommodated by crustal thickening in the onland regions of the Bird's Head plate. The rest of the convergence between the two plates is accommodated by the southward subduction of the oceanic plate beneath the Bird's Head plate along the New Guinea and Manokwari trenches (Puntodewo et al., 1994; Bird, 2003).

According to the Global CMT Project, the earthquake doublet of January 3, 2009 UT had similar seismic moments and thrust faulting mechanisms that corresponds to the faulting on the plate boundary along the New Guinea trench. These focal mechanisms are consistent with the direction of subduction of the oceanic slab beneath the Bird's Head plate. The New Britain and Solomon Islands regions located east of the Irian Jaya region are also well known for large shallow thrust events $\left(M_{\mathrm{w}}>7.0\right)$ that have tendency to occur in closely related pairs (Table 1). These earthquake doublets are represented by the similarly sized events that occur at nearly the same time and location (Lay and Kanamori, 1980; Schwartz et al., 1989; Park and Mori, 2007). Lay and Kanamori (1980) reported that such a doublet behavior is a true characteristic of the regions due to the complex tectonic settings. They explained the doublet events as a result of the mechanism of seismic triggering that reflects the state of stress on the fault plane and lithospheric coupling between the Pacific and Australia plates.

The 2009 Irian Jaya earthquake doublet may correspond to the shallow thrust doublets in the New Britain and Solomon Islands regions (Fig. 1). Detailed knowledge of 


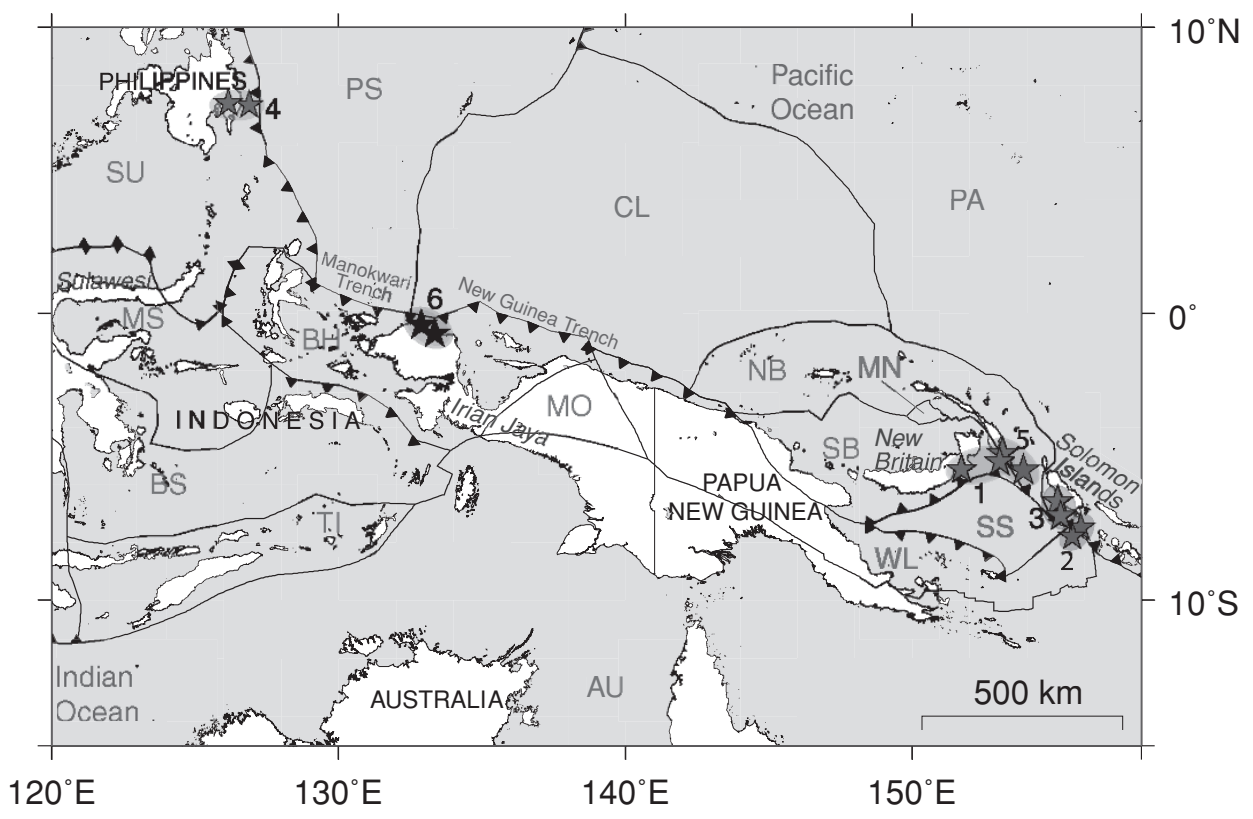

Fig. 1. Tectonic features of the Eastern Indonesia and Papua New Guinea after Bird (2003). The stars represent the epicenters of the doublet events discussed in this study (their detailed information is given in Table 1). Heavy black lines denote the boundaries of the Sunda (SU), Molucca Sea (MS), Banda Sea (BS), Timor (TI), Bird's Head (BH), Maoke (MO), Australia (AU), Caroline (CL), Woodlark (WU), North Bismarck (NB), Manus (MN), South Bismarck (SB), Solomon Sea (SS), Philippine Sea (PS), and Pacific (PA) plates (after Bird, 2003).

Table 1. Parameters of earthquake doublets in the region. Doublet numbers correspond to Fig. 1. We define the earthquake doublet as being composed of two earthquakes with similar sizes: difference in moment magnitude of the events must be $\leq 0.3$.

\begin{tabular}{|c|c|c|c|c|c|c|c|}
\hline Doublet no. & Event & $\begin{array}{c}\text { Origin time } \\
(\mathrm{UT})\end{array}$ & $\begin{array}{l}\text { Latitude } \\
\text { (deg) }\end{array}$ & $\begin{array}{c}\text { Longitude } \\
(\mathrm{deg})\end{array}$ & $\begin{array}{c}\text { Depth } \\
(\mathrm{km})\end{array}$ & $M_{\mathrm{w}}$ & Reference \\
\hline \multirow[t]{2}{*}{1} & July 14,1971 & $06: 11: 29$ & -5.52 & 153.86 & 43 & 8.0 & Lay and Kanamori (1980) \\
\hline & July 26, 1971 & $01: 23: 21$ & -4.93 & 153.18 & 43 & 8.1 & \\
\hline \multirow[t]{2}{*}{2} & Jan. 31, 1974 & 23:30:05 & -7.50 & 155.90 & 16 & 7.3 & \\
\hline & Feb. 01, 1974 & $03: 12: 33$ & -7.80 & 155.60 & 16 & 7.4 & \\
\hline \multirow[t]{2}{*}{3} & July 20, 1975 & $14: 37: 39$ & -6.60 & 155.10 & 43 & 7.6 & \\
\hline & July 20, 1975 & $19: 54: 27$ & -7.10 & 155.20 & 43 & 7.3 & \\
\hline \multirow[t]{2}{*}{4} & May 17,1992 & 09:49:19 & 7.24 & 126.64 & 32 & 7.1 & Global CMT Catalog \\
\hline & May 17, 1992 & $10: 15: 30$ & 7.19 & 126.76 & 33 & 7.2 & \\
\hline \multirow[t]{2}{*}{5} & Nov. 16, 2000 & $07: 42: 16$ & -5.23 & 153.10 & 26 & 7.5 & Park and Mori (2007) \\
\hline & Nov. 16, 2000 & 21:01:56 & -5.49 & 151.78 & 36 & 7.4 & \\
\hline \multirow[t]{2}{*}{6} & Jan. 03, 2009 & $19: 43: 54$ & -0.51 & 132.78 & 15 & 7.6 & This study \\
\hline & Jan. 03, 2009 & $22: 33: 42$ & -0.71 & 133.34 & 12 & 7.4 & \\
\hline
\end{tabular}

the source process and slip distribution of this earthquake doublet is essential for understanding the state of stress in the Irian Jaya region. It is also helpful for understanding the triggering mechanism of earthquakes in a subduction zone. To study the source process and slip distribution, we performed source inversions using teleseismic body-wave data.

\section{Data and Method}

Teleseismic records collected by the Data Management Center of the Incorporated Research Institute for Seismology (IRIS-DMC) were used to infer the source processes of the 2009 Irian Jaya earthquake doublet. We retrieved broadband seismograms from IRIS-DMC for the stations at epicentral distances of 30 to 100 degrees, taking into consideration the quality of records and the azimuthal coverage of the stations. 45 and 44 vertical $P$-wave components were selected for the 19:43 UT and 22:33 UT events, respectively. The global distribution of the selected teleseismic stations is shown in Fig. 2. In order to keep similar conditions of analysis, the same stations were used for both the 19:43 UT and 22:33 UT events, as far as possible. The only exception is DGAR station, where no record was available for the 22:33 UT event (Fig. 2). The original velocity waveforms from the selected stations were windowed for 90 or $80 \mathrm{~s}$, starting $20 \mathrm{~s}$ before the $P$-wave arrival, band-pass filtered between 0.005 and $1 \mathrm{~Hz}$, and then converted into ground displacements at a sampling interval of $0.5 \mathrm{~s}$.

To obtain the source processes of the 2009 Irian Jaya earthquake doublet, we analyzed each of the events separately using the standard fault parameterization and waveform inversion scheme by Kikuchi and Kanamori (1991) and Kikuchi et al. (2003) with the Green's functions calculated after Kikuchi and Kanamori (1991). The velocity 


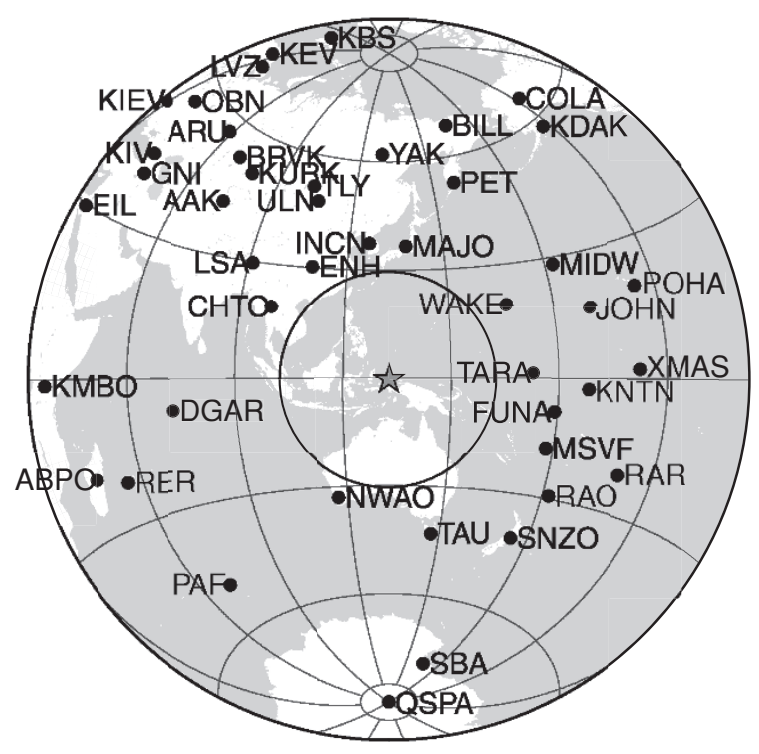

Fig. 2. Global distribution of teleseismic broadband stations (black dots) used for the waveform inversions of the 19:43 UT and 22:33 UT events. The stars represent the epicenters of the events, which are completely overlapped. The inner and outer large circles represent the epicentral distances of 30 and 100 degrees, respectively. Map is drawn onto an azimuthal equidistant projection.

Table 2. Velocity structure derived from the Jeffreys-Bullen model.

\begin{tabular}{cccc}
\hline $\begin{array}{c}V_{p} \\
(\mathrm{~km} / \mathrm{s})\end{array}$ & $\begin{array}{c}V_{s} \\
(\mathrm{~km} / \mathrm{s})\end{array}$ & $\begin{array}{c}\text { Density } \\
\left(10^{3} \mathrm{~kg} / \mathrm{m}^{3}\right)\end{array}$ & $\begin{array}{c}\text { Thickness } \\
(\mathrm{km})\end{array}$ \\
\hline 5.57 & 3.36 & 2.65 & 15.0 \\
6.50 & 3.74 & 2.78 & 18.0 \\
8.10 & 4.68 & 3.30 & - \\
\hline
\end{tabular}

structure assumed for the theoretical teleseismic body wave calculation is based on the Jeffreys-Bullen model (Table 2; Jeffreys and Bullen, 1958).

We assumed that the rupture occurred on a single fault plane and adopted the epicenter at $\left(0.51^{\circ} \mathrm{S}, 132.78^{\circ} \mathrm{E}\right)$ with a focal depth of $35 \mathrm{~km}$ for the 19:43 UT event, and the epicenter at $\left(0.713^{\circ} \mathrm{S}, 133.336^{\circ} \mathrm{E}\right)$ with a focal depth of $35 \mathrm{~km}$ for the 22:33 UT event, as initially reported by USGS. To determine the focal mechanism and relocate the focuses of the events we performed the point source inversions of Kikuchi and Kanamori (1991). The best waveform fit was achieved by the focal depths of $15 \mathrm{~km}$ for the 19:43 UT event and $10 \mathrm{~km}$ for the 22:33 UT event. These values correspond to the centroid depth of the entire fault motion, rather than the depth of the rupture starting point. The resultant best fit solution of the point source analysis indicate reverse faulting with low-angle south-dipping fault planes: (strike, dip, slip $)=\left(107^{\circ}, 31^{\circ}, 67^{\circ}\right)$ and $\left(100^{\circ}, 28^{\circ}, 57^{\circ}\right)$ for the 19:43 UT and 22:33 UT events, respectively (Fig. 7). Those agree with one of the nodal planes of $\left(98^{\circ}, 28^{\circ}, 49^{\circ}\right)$ and $\left(99^{\circ}, 25^{\circ}, 68^{\circ}\right)$ from the solutions by the Global CMT Project. This agreement supports the assumption that the same thrust faulting mechanism along the subducting plate boundary generated both events.

We next inverted the waveforms for the spatio-temporal slip distributions on the finite fault planes (Kikuchi et al.,
2003) with the geometry determined from the point source analyses. We also performed grid search in order to determine the depths of the rupture starting points for the finite fault planes of both the events by varying the depth at $1 \mathrm{~km}$ interval. The dimensions of the fault planes for both the events were determined based on the aftershock distributions and the scaling of characterized slip models for Japanese plate-boundary earthquakes proposed by Murotani et al. (2008). The fault parameterization and the results of the waveform inversions are discussed below separately for each event.

\section{Results}

\subsection{January 3, 2009, 19:43 UT event}

The fault plane is assumed to be $150 \mathrm{~km}$ in length by $60 \mathrm{~km}$ in width, based on the distribution of USGS locations for the aftershocks preceding the 22:43 UT event. We then divided the fault plane into $15 \times 6$ subfaults with a dimension of $10 \mathrm{~km}$. The temporal variation for the momentrate function of each subfault is represented by a series of four overlapping triangle functions with $2 \mathrm{~s}$ half-durations and $2 \mathrm{~s}$ lag offsets. We performed the waveform inversions for several rupture front velocities and hypocenter depths, and chose the best-fit solution. The rigidity around the fault plane was assumed to be $\mu=35 \mathrm{GPa}$ from the velocity structure model (Table 2).

The best-fit solution of the waveform inversions is shown in Figs. 3 and 4. This solution, minimizing the residuals between the observed and synthetic waveforms, was obtained for the rupture front velocity of $2.5 \mathrm{~km} / \mathrm{s}$. The depth of the rupture starting point estimated from the grid search analysis is $15 \mathrm{~km}$, which confirms the result of the point source analysis. Figure 3 compares the observed and synthetic seismograms showing good agreement between them. Figure 4(a) illustrates the fault geometry determined by the point source analysis together with the incident points of teleseismic body waves. The source time function (Fig. 4(b)) indicates that a total seismic moment $M_{0}$ of $3.28 \times 10^{20} \mathrm{~N} \mathrm{~m}\left(M_{\mathrm{w}} 7.6\right)$ was released during a period of $46 \mathrm{~s}$. The slip distribution over the fault plane (Fig. 4(c)) shows the existence of a main asperity with the maximum slip of about $5.9 \mathrm{~m}$ near the hypocenter. Most of the rupture occurred on the northwestern part of the fault plane, covering on area of about $100 \mathrm{~km}$ in length by $60 \mathrm{~km}$ in width. This main asperity extends towards the shallow part of the fault plane. A few secondary asperities smaller than the main one can be also found in the slip distribution. The fault rupture bilaterally propagated from the hypocenter, and its eastern branch reached the hypocenter of the second event (Fig. 4(c)).

\subsection{January 3, 2009, 22:43 UT event}

For the second event at 22:43 UT, we defined the fault plane dimension to be $90 \mathrm{~km}$ in length by $40 \mathrm{~km}$ in width based on the scaling relation proposed by Murotani et al. (2008) and constraining the fault plane from intersecting the free surface. It is impossible to use the aftershock distribution in order to define the fault plane of the event, since the aftershocks of the 19:33 UT event and the aftershocks of the 22:43 UT event are mixed temporally and spatially. The fault plane was divided into $9 \times 4$ subfaults with a dimension 


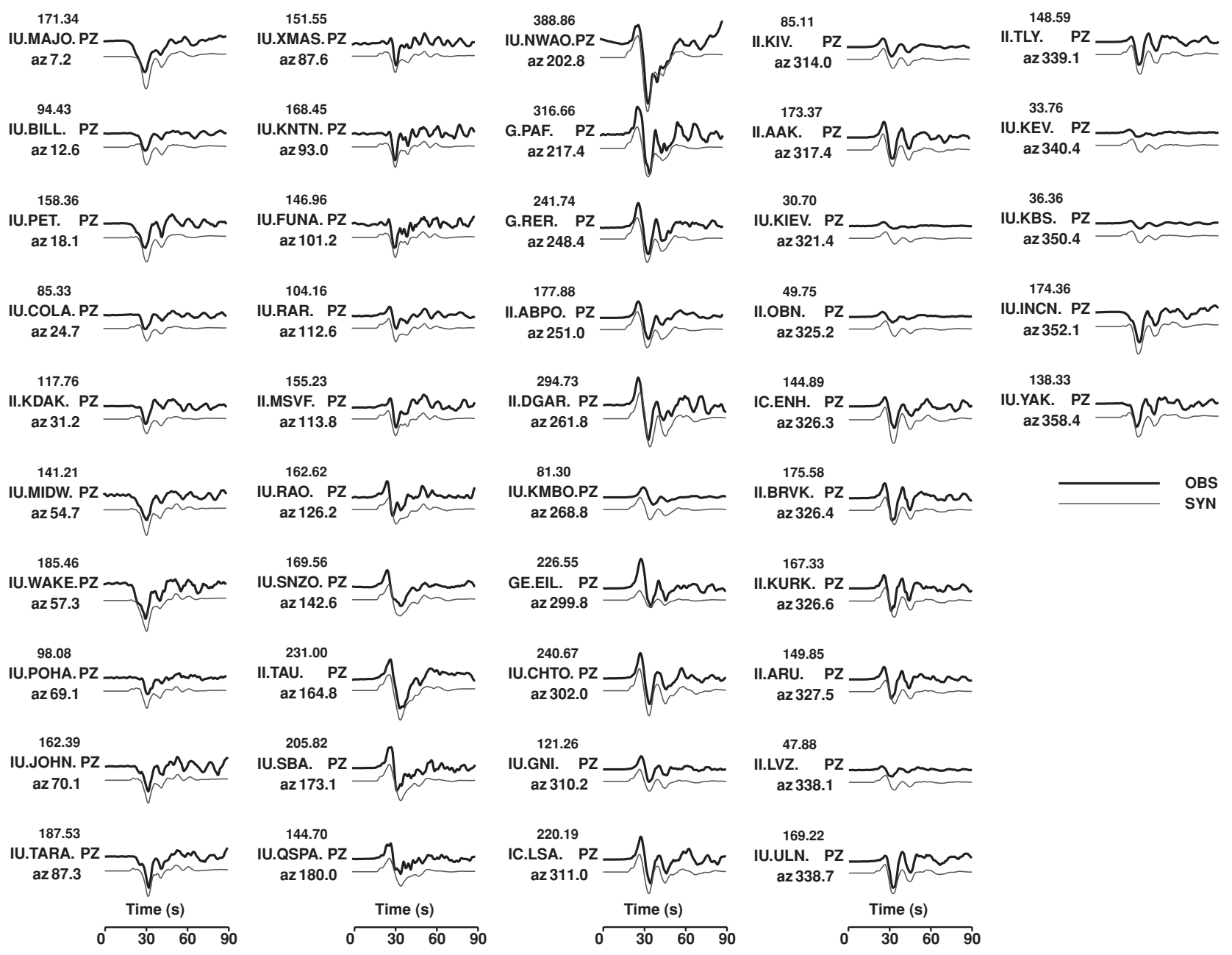

Fig. 3. Comparison of the observed (solid black lines) and synthetic (gray lines) displacement waveforms for the best-fit solution of the 19:43 UT event. The number above the station code indicates the maximum amplitude in micro-meter and the number below the station code is a source-to-station azimuth.

(a) $(107 ., 31 ., 67$.

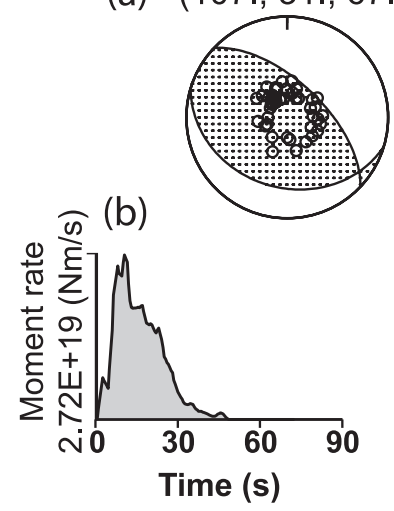

(c)

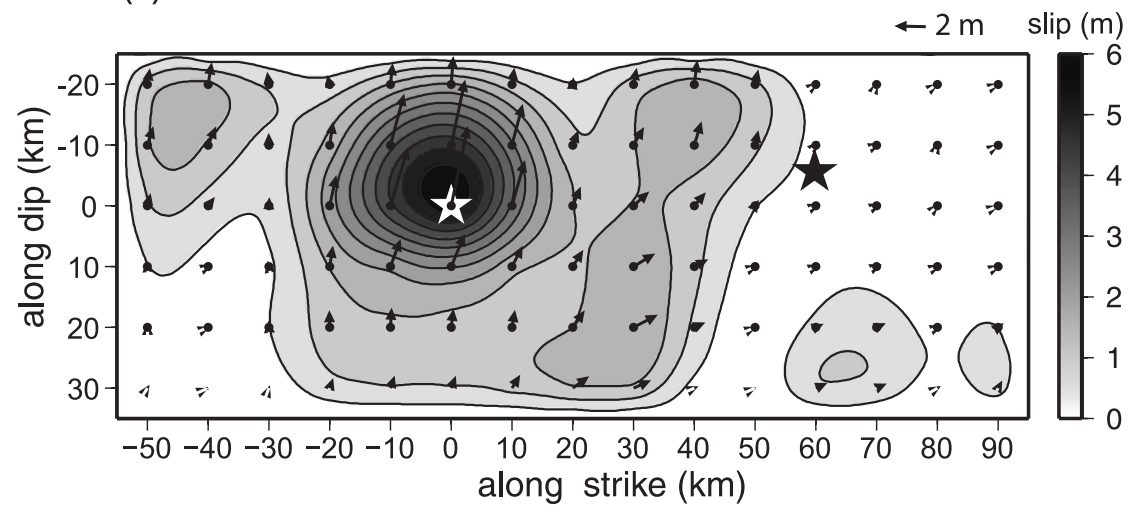

Fig. 4. Result of the teleseismic waveform inversion for the 19:43 UT event. (a) focal mechanism solution, (b) moment-rate function, and (c) slip distribution plotted at contour intervals of $0.5 \mathrm{~m}$. The white and the black stars indicate the hypocenters (rupture starting points) of the 19:43 UT and 22:33 UT events, respectively. The arrows denote slip vectors of the hanging wall relative to the footwall.

of $10 \mathrm{~km}$. As for the 19:33 UT event, the moment-rate function of each subfault was decomposed into a series of four triangle functions with $2 \mathrm{~s}$ half-durations and $2 \mathrm{~s}$ lag offsets. The inversion method and assumed rigidity were the same as in the case of the 19:33 UT event.

The comparison of the observed and synthetic waveforms is given in Fig. 5 and the best-fit model is shown in Fig. 6. The seismic moment $M_{0}$ is estimated to be $1.53 \times 10^{20} \mathrm{~N} \mathrm{~m}$ $\left(M_{\mathrm{w}}\right.$ 7.4). The source time function (Fig. 6(b)) suggests the total rupture time to be about $25 \mathrm{~s}$. The depth of the rupture starting point is found to be $12 \mathrm{~km}$. The slip distribution over the fault plane (Fig. 6(c)) shows a single asperity with 


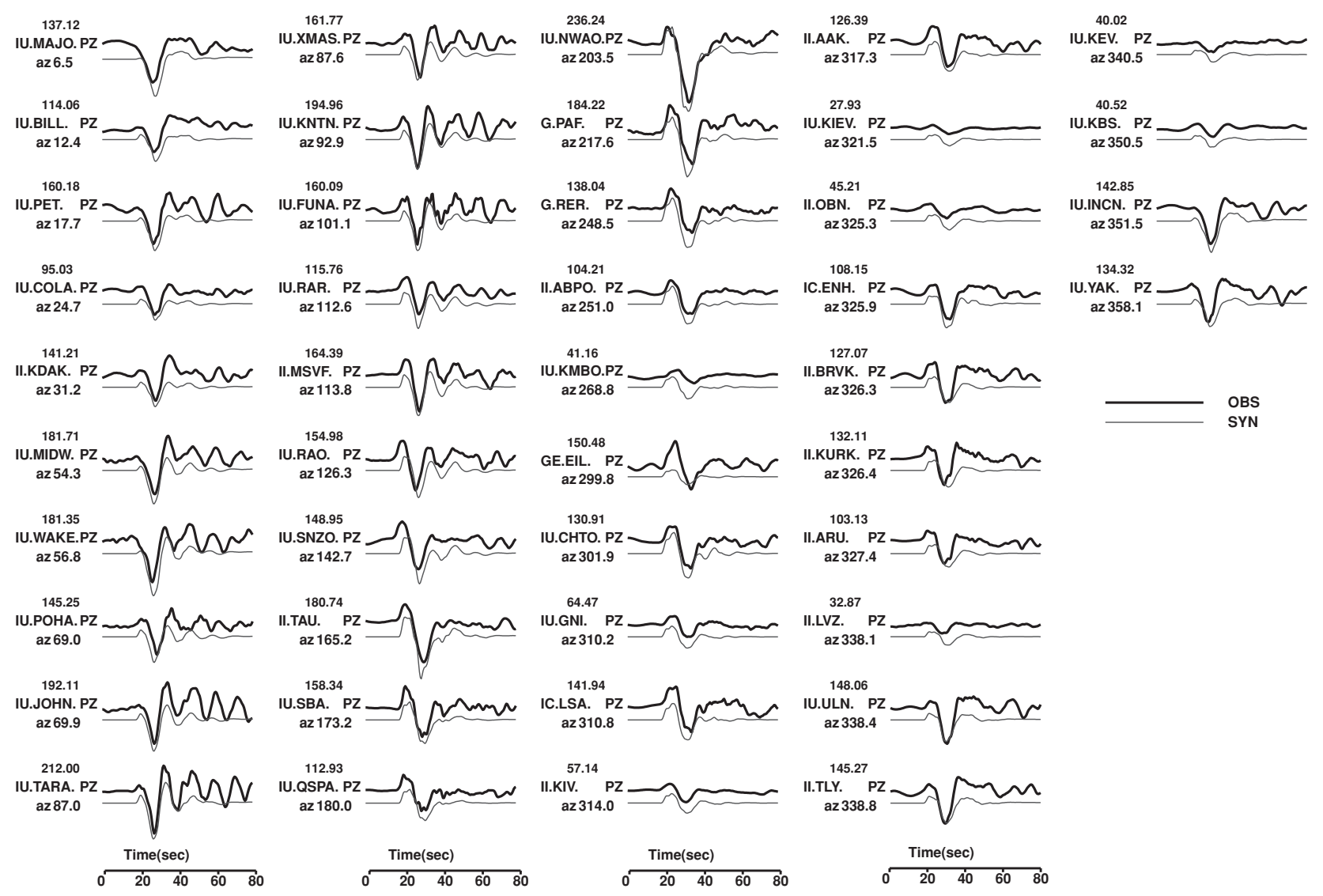

Fig. 5. Comparison of the observed (solid black lines) and synthetic (gray lines) displacement waveforms for the best-fit solution of the 22:33 UT event. The number above the station code indicates the maximum amplitude in micro-meter and the number below the station code is a source-to-station azimuth.

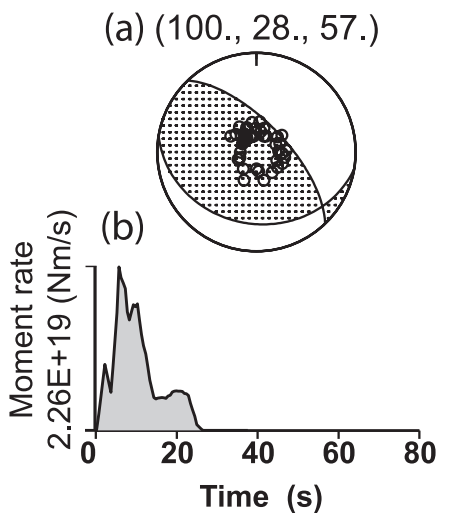

(c)

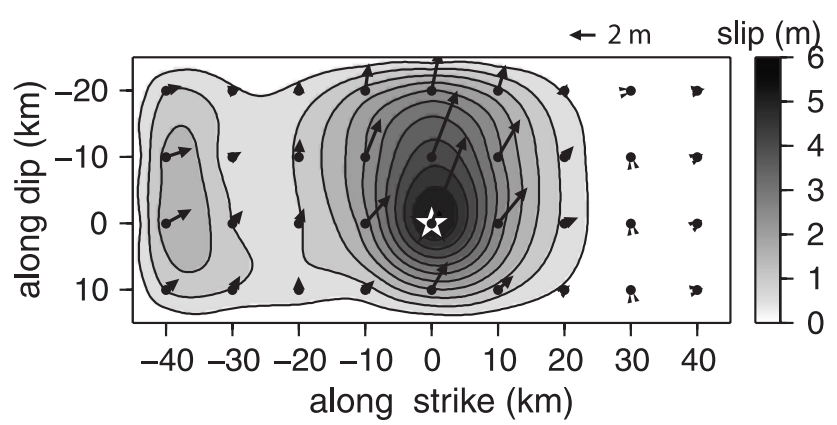

Fig. 6. Result of the teleseismic waveform inversion for the 22:33 UT event. (a) focal mechanism solution, (b) moment-rate function, and (c) slip distribution plotted at contour intervals of $0.5 \mathrm{~m}$. The star indicates the hypocenter (rupture starting point), and the arrows denote slip vectors of the hanging wall relative to the footwall.

the maximum slip of $5.6 \mathrm{~m}$ near the hypocenter, and the rupture extended towards the shallow part of the fault, similarly to the 19:33 UT event. The best solution for the rupture velocity was found to be $2.8 \mathrm{~km} / \mathrm{s}$. It can be observed that the total asperity area of this event is smaller than that for the 19:33 UT event.

\section{Discussion and Conclusions}

Figure 7 shows the horizontal projections of the rupture areas and slip distributions of the 2009 Irian Jaya earthquake doublet determined by the teleseismic waveform in- versions. The rupture areas are consistent with the aftershock distribution and the scaling relation by Murotani et al. (2008). The doublet events have almost the same focal mechanism and similar seismic moments of $3.28 \times 10^{20} \mathrm{~N} \mathrm{~m}$ and $1.53 \times 10^{20} \mathrm{~N} \mathrm{~m}$. The focal mechanisms agree with the southward underthrusting of the Pacific Sea plate beneath the Bird's Head plate along the New Guinea trench, suggesting that the doublet occurred on the boundary of these two plates. According to the slip distributions of both the events (Figs. 4, 6, and 7), significant slips exceeding $5.0 \mathrm{~m}$ occurred near the hypocenters. The slip distributions of the 


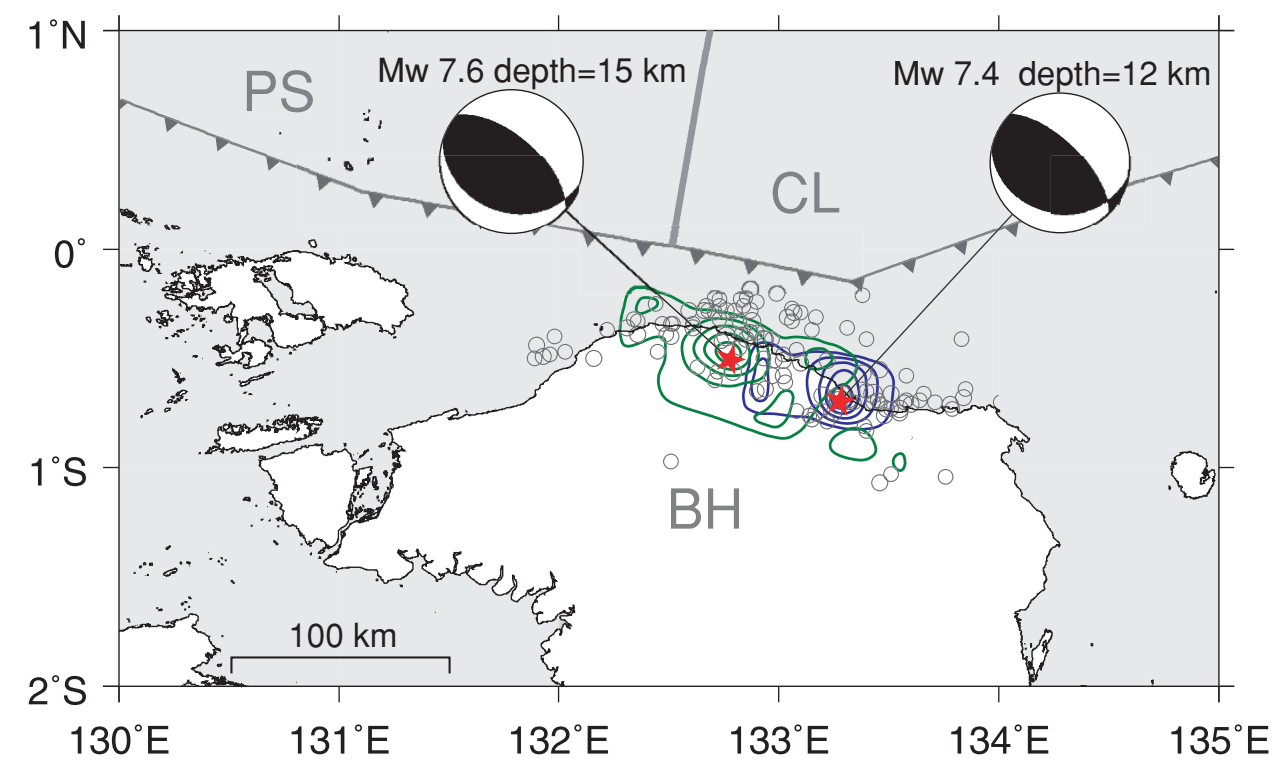

Fig. 7. Projections of the slip distributions for the 2009 Irian Jaya earthquake doublet onto the tectonic map (green: 19:43 UT event, blue: 22:33 UT event). The contour interval is $1.0 \mathrm{~m}$; the first contour given is $0.5 \mathrm{~m}$. The red stars represent the USGS epicenter locations. The aftershocks of both the events determined by USGS within a month after the events are plotted by gray open circles. The focal mechanisms obtained in the present study are also shown with the moment magnitudes and focal depths.

earthquakes look to be complementary to each other. The rupture starting point (hypocenter) of the 22:43 UT event is located close to the eastern margin of the slip distribution of the 19:33 UT event. If we define an asperity to be a zone of slip larger than half of the maximum slip (Yamanaka and Kikuchi, 2004), it can be seen that both the events have compact asperities around the hypocenters. The asperities are well separated one from the other and much smaller than the whole rupture areas. The teleseismic waveforms generated by such asperities are rather simple and impulsive (Figs. 3 and 5).

The source characteristics of the 2009 Irian Jaya earthquake doublet are very similar to the Solomon Islands doublets (Fig. 1 and Table 1), as described by Lay and Kanamori (1980) and Park and Mori (2007). Lay and Kanamori (1980) first noted that large shallow earthquakes in the Solomon Islands and New Britain Islands regions tend to occur in closely related pairs. Events are typically separated by a few hours or several days in time and $50 \sim 100 \mathrm{~km}$ in space. This behavior has been attributed to a specific pattern of plate boundary heterogeneity consisting of small strong asperities spaced close together. The rupture of one asperity induces high, rapidly accumulated stress concentration in adjacent areas and can generate the second similar event. We expect the same triggering mechanism to be responsible for the doublet events of the January 3, 2009 in Irian Jaya. The distinct nature of this behavior can be attributed to the complex tectonic configuration of the area and implies the existence of localized strong coupling between the lithospheric plates along the New Guinea trench. However, it has to be noticed that even though the asperities of the doublet events of the January 3 , 2009 from Irian Jaya are well separated one from the other, there exist a significant overlap in the rupture areas of the first and second events. This may indicate that the actual mechanism of doublet triggering for these events is more complex than the one for the well separated earthquakes in the Solomon Islands and New Britain Islands (Lay and Kanamori, 1980). We would also point out that the number of large earthquake doublets $\left(M_{\mathrm{w}}>7.0\right)$ in the Irian Jaya region is much smaller than in the Solomon Islands region. This can be explained by lower seismicity along the New Guinea trench. The result of the GPS studies (Puntodewo et al., 1994; Bock et al., 2003) also explain the small number of large earthquake doublets by suggesting that the subduction along the New Guinea trench only partially accommodates the oblique convergence between the Pacific and Australia plates. The rest of the convergence is accommodated by crustal thickening in the inland part of the Bird's Head plate. This fact represents a significant difference between the Solomon Sea plate and the Bird's Head plate.

Acknowledgments. We acknowledge two anonymous reviewers for improvement of the manuscript, and Satoshi Kaneshima for editing. We thank the Data Management Center of the Incorporated Research Institute for Seismology and the United States Geological Survey for the teleseismic body wave data, and the Global CMT Project for their information on the events. Some figures were made using the Generic Mapping Tools software (Wessel and Smith, 1995). This research was partly supported by SATREPS from JST and JICA.

\section{References}

Bird, P., An updated digital model of plate boundaries, Geochem. Geophys. Geosyst., 4, 1027-1080, 2003.

Bock, Y., L. Prawirodirdjo, J. F. Genrich, C. W. Stevens, R. McCaffrey, C. Subarya, S. S. O. Puntodewo, and E. Calais, Crustal motion in Indonesia from Global Positioning System measurements, J. Geophys. Res., 108(B8), 2367, doi:10.1029/2001JB000324, 2003.

DeMets, C., R. G. Gordon, D. F. Agrus, and S. Stein, Current plate motion, Geophys. J. Int., 101, 425-478, 1990.

Global Centroid Moment Tensor Catalog, http://www.globalcmt.org/, 2009.

Global Disaster and Coordination System (GDACS), Tsunami report, http://gdacs.org, 2009.

Jeffreys, H. and K. E. Bullen, Seismological Tables, 50 pp., British Asso- 
ciation for the Advancement of Science, London, 1958.

Kikuchi, M. and H. Kanamori, Inversion of complex body wave-III, Bull. Seismol. Soc. Am., 81, 2335-2350, 1991.

Kikuchi, M., M. Nakamura, and K. Yoshikawa, Source rupture process of the 1944 Tonankai earthquake and the 1945 Mikawa earthquake derived from low-gain seismograms, Earth Planets Space, 55, 159-172, 2003.

Lay, T. and H. Kanamori, Earthquake doublets in the Solomon Islands, Phys. Earth Planet. Inter., 21, 283-304, 1980.

Milsom, J., D. Masson, G. Nichols, N. Sikumbang, B. Dwiyanto, L. Parson, and H. Kallagher, The Manokwari trough and the west end of the New Guinea trench, Tectonics, 11, 145-153, 1992.

Murotani, S., H. Miyake, and K. Koketsu, Scaling of characterized slip models for plate-boundary earthquakes, Earth Planets Space, 60, 987991, 2008.

Park, S.-C. and J. Mori, Are asperity patterns persistent? Implication from large earthquakes in Papua New Guinea, J. Geophys. Res., 112, B03303, doi:10.1029/2006JB004481, 2007.

Puntodewo, S. S. O., R. McCaffrey, E. Calais, Y. Bock, J. Rais, C. Sub- arya, R. Poewariardi, C. Stevens, J. Genrich, Fauzi, P. Zwick, and S. Wdowinski, GPS measurements of crustal deformation within the Pacific-Australia plate boundary zone in Irian Jaya, Indonesia, Tectonophysics, 237, 141-153, 1994.

Schwartz, S. Y., T. Lay, and L. J. Ruff, Source process of the great 1971 Solomon Islands doublet, Phys. Earth Planet. Inter., 56, 294-310, 1989. United States Geological Survey, Earthquake Summary Poster, http://earthquake.usgs.gov/eqcenter/eqarchives/poster/ 2009/20090103.php, 2009.

Wessel, P. and W. H. F. Smith, New version of the Generic Mapping Tools released, EOS Trans. AGU, 76, 329, 1995.

Yamanaka, Y. and M. Kikuchi, Asperity map along the subduction zone in northeastern Japan inferred from regional seismic data, J. Geophys. Res., 109, B07307, doi:10.1029/2003JB002683, 2004.

N. Poiata (e-mail: natalia@eri.u-tokyo.ac.jp), K. Koketsu, and H. Miyake 